\title{
High exogenous concentrations of phenoxyacetic acid are crucial for a high penicillin V productivity in Penicillium chrysogenum
}

\author{
Claus M. Henriksen, $†$ Jens Nielsen and John Villadsen
}

Center for Process

Biotechnology, Technical University of Denmark,

DK-2800 Lyngby, Denmark
Author for correspondence: Jens Nielsen. Tel: +454525 2696. Fax: +4545884148. e-mail: jn@ibt.dtu.dk

\begin{abstract}
A high-penicillin-yielding strain of Penicillium chrysogenum was grown in continuous culture on a chemically defined medium with glucose as the growth-limiting component. The cultivations were operated at a constant dilution rate of $0.05 \mathrm{~h}^{-1}$ and the feed concentration of the penicillin $\mathrm{V}$ sidechain precursor phenoxyacetic acid was varied between 0 and $6.5 \mathrm{~g} \mathrm{I}^{-1}$. Subsequent formation of penicillin $\mathbf{V}$ and by-products related to the penicillin biosynthetic pathway was monitored at steady state. It was established that the concentration of phenoxyacetic acid in the growth medium had to be kept $h i g h$ to obtain a high productivity of penicillin $V$. The specific production rate of penicillin $\mathbf{V}$ as a function of the phenoxyacetic acid concentration followed Michaelis-Menten-type kinetics, from which an overall apparent $K_{m}$ value of $42 \mathrm{mM}$ for the incorporation of intracellular phenoxyacetic acid into penicillin $V$ could be obtained. High phenoxyacetic acid concentrations tended to lower the formation of the by-products 6-aminopenicillanic acid and 8hydroxypenillic acid. Furthermore the undesirable loss of the pathway intermediate isopenicillin $\mathbf{N}$ into the extracellular medium was lowered, whereas the opposite effect was observed for the pathway intermediate $\delta$-(L- $\alpha$ aminoadipyl)-L-cysteinyl-D-valine and the by-product 6-oxo-piperidine-2carboxylic acid, the $\delta$-lactam form of $\alpha$-aminoadipic acid.
\end{abstract}

Keywords: Penicillium chrysogenum, phenoxyacetic acid, steady-state continuous cultivation, penicillin $\mathrm{V}$, by-products

\section{INTRODUCTION}

Amongst the bulk penicillins being produced industrially by fed-batch cultivations of Penicillium chrysogenum, penicillins $V$ and $G$ are by far the most important. These two penicillins are formed when the cultivation medium is supplied with phenoxyacetic acid (POA) and phenylacetic acid, respectively. In its natural habitat $P$. chrysogenum produces penicillins DF, F and $\mathrm{K}$, which contain, respectively, hexenoic acid, $\Delta^{3}$-hexenoic acid and octenoic acid as sidechains. All the sidechain precursors are weak acids and are characterized as being amphipathic, i.e. one end of the sidechain precursor is hydrophobic while the other end is hydrophilic. The hydrophobic end is probably required both for the

†Present address: Chr. Hansen AVS, Department of Physiology and Metabolism, DK-2970 Hørsholm, Denmark. sidechain precursor and for the synthesized penicillin to diffuse readily across the plasma membrane. The different penicillins are formed when the sidechain precursors are coupled to the penam ring structure by the enzyme acyltransferase, using either isopenicillin $\mathrm{N}$ (IPN), 6-aminopenicillanic acid (6-APA) or another penicillin as substrate (Alvarez et al., 1993). However, the sidechain precursors have to be 'activated' before they become substrates for the acyltransferase. It is generally agreed that the activated form of the sidechain precursor is the CoA-ester form, but the mechanism behind this activation has still not been fully elucidated.

We have previously studied the influence of POA on the growth energetics of steady-state continuous cultures of P. chrysogenum (Henriksen et al., 1998). Since we found no negative physiological effects on the growth of $P$. chrysogenum from high extracellular POA concentrations at an extracellular $\mathrm{pH}$ of 6.50 , the next step was 
to establish experimentally whether a high concentration of the sidechain precursor is a requirement for obtaining high productivities of penicillin. Here we report the influence of the extracellular POA concentration on the specific formation rates of penicillin $\mathrm{V}$ and by-products related to the penicillin biosynthetic pathway, i.e. $\delta$-(L- $\alpha$-aminoadipyl)-L-cysteinyl-D-valine (ACV), IPN, 6-APA, 8-hydroxypenillic acid (8-HPA) and 6-oxopiperidine-2-carboxylic acid (OPC), the $\delta$ lactam form of $\alpha$-aminoadipic acid.

\section{METHODS}

Strain. The high-penicillin-yielding strain of $P$. chrysogenum used was kindly donated by Novo Nordisk A/S, Bagsværd, Denmark. It is known to yield about $20-25 \mathrm{~g}$ penicillin $\mathrm{V}$ $\mathrm{l}^{-1}$ after $200 \mathrm{~h}$ fed-batch cultivation (Jørgensen et al., 1995).

Media. Both the batch medium and the feed during continuous operation were defined. The batch medium contained $\left(1^{-1}\right)$ :

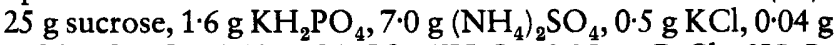
$\mathrm{FeSO}_{4} .7 \mathrm{H}_{2} \mathrm{O}, 0.10 \mathrm{~g} \mathrm{MgSO}_{4} .7 \mathrm{H}_{2} \mathrm{O}, 0.05 \mathrm{~g} \mathrm{CaCl} .2 \mathrm{H}_{2} \mathrm{O}$, $0.5 \mathrm{ml}$ Pluronic F68 (Fluka) and $5 \mathrm{ml}$ trace metal solution. The feed was similar to the batch medium except for the sucrose, which was replaced by $15 \mathrm{~g}$ glucose $\mathrm{l}^{-1}$ (sterilized separately), and the phenoxyacetic acid, which was added in various concentrations up to $6.5 \mathrm{~g} \mathrm{I}^{-1}$ (added as sodium phenoxyacetate). At steady-state conditions growth was limited by glucose. The trace metal solution contained $\left(1^{-1}\right): 1.0 \mathrm{~g}$ $\mathrm{CuSO}_{4} .5 \mathrm{H}_{2} \mathrm{O}, 4.0 \mathrm{~g} \mathrm{ZnSO}_{4} .7 \mathrm{H}_{2} \mathrm{O}$ and $4.0 \mathrm{~g} \mathrm{MnSO}$. $\mathrm{H}_{2} \mathrm{O}$.

Cultivation conditions. All cultivations were carried out in a high-performance Chemap bioreactor with an approximate working volume of 6.51 (Nielsen \& Villadsen, 1993). The bioreactor was placed on a load cell with an accuracy of $\pm 20 \mathrm{~g}$ and operated for constant-mass continuous cultivation at a fixed dilution rate of $0.05 \mathrm{~h}^{-1}$. The temperature, $\mathrm{pH}$, aeration rate and head space pressure were kept constant at $25.0^{\circ} \mathrm{C}$, $6.50,1$ vol. vol. ${ }^{-1} \mathrm{~min}^{-1}$ and $1.5 \mathrm{bar}$, respectively. The agitation rate was kept constant at a level sufficiently high to maintain a dissolved oxygen tension above $100 \%$ (air saturation at 1 bar). The batch cultures were inoculated with spores from rice cultures to an initial concentration of $4.6 \times 10^{8}$ spores $\mathrm{kg}^{-1}$. All rice cultures were prepared from the same stock of vials containing lyophilized spores. Continuous cultivation was initiated at the time when all carbohydrates were exhausted, leaving gluconic acid as the main carbon source (sucrose is initially hydrolysed enzymically by invertase to glucose and fructose, and during the catabolism of glucose substantial amounts of gluconic acid are formed by the enzyme glucose oxidase).

Sampling. Cell-free samples were taken automatically by means of an in situ membrane module (Christensen et al., 1991) and collected for later analysis in a fraction collector positioned in a refrigerator. Biomass samples were taken manually. For dry weight measurements the samples were filtered, washed with water and dried at $105^{\circ} \mathrm{C}$ until constant weight.

Steady state. Attainment of steady state was based on measurements of the biomass concentration, the oxygen consumption rate, the carbon dioxide evolution rate and the concentration of penicillin $\mathrm{V}$ in the cell-free samples. As illustrated by Christensen et al. (1995), the strain of $P$. chrysogenum we used is genetically unstable, resulting in a decrease in the penicillin productivity after more than 6-7 residence times. Hence all steady-state data were obtained during the first 6 residence times and after the steady state had been reached.

HPLC analysis of penicillin. Penicillin V, penicilloic acid V, $p$ hydroxypenicillin V, POA and $p$-hydroxyPOA were analysed as described by Christensen et al. (1994). Penicillin V, penicilloic acid $\mathrm{V}$ and $p$-hydroxypenicillin $\mathrm{V}$ were pooled together by converting penicilloic acid $\mathrm{V}$ and $p$-hydroxypenicillin $\mathrm{V}$ into penicillin $\mathrm{V}$ equivalents. Similarly, $p$ hydroxyPOA was converted into POA equivalents and reported as such.

HPLC analysis of 6-APA, 8-HPA, OPC and IPN. 6-APA, 8-HPA, OPC and IPN were quantified according to Henriksen $e t$ al. (1997). IPN was a kind gift from Gist-Brocades.

HPLC analysis of thiol-group-containing metabolites. Thiolgroup-containing metabolites, including ACV, glutathione, cysteine and homocysteine, were measured by an HPLC method based on precolumn derivatization with the fluorescing reagent monobromobimane as follows.

HPLC equipment. The HPLC equipment was from Waters and consisted of two pumps (type 510), an autosampler/ autoinjection system (type WISP 712), a column oven (type TCM) and a scanning fluorescence detector (type 470). The autoinjection system was equipped with a built-in cooling unit, maintaining the sample temperature at $4-5^{\circ} \mathrm{C}$. Data acquisition and pump control were performed by the 810 Baseline software from Waters. The column used was a NovaPak C-18 (300 $\times 3.9 \mathrm{~mm}$ ) with $4 \mu \mathrm{m}$ packing (Waters, part no. 11695 ) with a Nova-Pak C-18 precolumn (Waters, part no. 15220).

Eluents. The eluents were prepared with Milli-Q water, microfiltered through a filter with a pore size of $0.45 \mu \mathrm{m}$ (Millipore catalogue no. HVLP4700) and degassed for 1015 min by means of ultrasound. The two eluents $A$ and $B$ consisted of $85 \%(\mathrm{v} / \mathrm{v}) 43 \mathrm{mM}$ acetic acid (Merck) $+15 \%$ (v/v) methanol (Merck) and $10 \%(\mathrm{v} / \mathrm{v}) 43 \mathrm{mM}$ acetic acid $+90 \%(\mathrm{v} / \mathrm{v})$ methanol, respectively. The $\mathrm{pH}$ of both eluents was adjusted to $4 \cdot 0$ by $18 \mathrm{M} \mathrm{H}_{2} \mathrm{SO}_{4}$.

Gradient. The mobile phase was changed as a function of time as follows : $0-14 \mathrm{~min} 100 \%$ (v/v) A; 14-17 min linear gradient to $85 \% \mathrm{~A}$ and $15 \% \mathrm{~B} ; 17-32 \mathrm{~min} 85 \% \mathrm{~A}$ and $15 \% \mathrm{~B}$; $32-42 \mathrm{~min}$ linear gradient to $20 \% \mathrm{~A}$ and $80 \% \mathrm{~B} ; 42-43 \mathrm{~min}$ $20 \% \mathrm{~A}$ and $80 \% \mathrm{~B} ; 43-46 \mathrm{~min}$ linear gradient to $100 \% \mathrm{~A}$; 46-55 min $100 \%$ A.

Separation and detection. The separation temperature and the flow of the mobile phase were set at $35^{\circ} \mathrm{C}$ and $1.0 \mathrm{ml} \mathrm{min}{ }^{-1}$, respectively. Fluorescence was detected with excitation at $370 \mathrm{~nm}$ and emission at $480 \mathrm{~nm}$. The injection volume was $10 \mu \mathrm{l}$. Under these separation conditions the retention times within the same series of 10 measurements were as follows: cysteine, $4.56 \pm 0.01 \mathrm{~min}$; glutathione, $6.03 \pm 0.01 \mathrm{~min}$; homocysteine, $7.50 \pm 0.01 \mathrm{~min}$; ACV, $28.04 \pm 0.04 \mathrm{~min}$. Detection was linear up to $50 \mu \mathrm{M}$ for all four components with a relative standard deviation of $0.6 \%, 1.0 \%, 0.8 \%$ and $1.0 \%$ for the peak area, respectively. The limit of detection was in the lower micromolar area.

Standards. Glutathione, cysteine and homocysteine were from Sigma. Bis-ACV was kindly supplied by Gist-Brocades. Samples containing $40 \mu \mathrm{l} 1.25 \mathrm{mM}$ of each standard dissolved in $50 \mathrm{mM}$ phosphate buffer, $\mathrm{pH} 2 \cdot 5$, were stored at $-20^{\circ} \mathrm{C}$ and thawed on ice prior to analysis.

Sample preparation and derivatization. A $40 \mu \mathrm{l}$ volume of each standard and sample from the cultivations was reduced by adding $10 \mu \mathrm{l}$ freshly prepared $\mathrm{NaBH}_{4}\left(100 \mathrm{mg} \mathrm{ml}^{-1}\right.$; Sigma) 
Table 1. Symbols and abbreviations

\begin{tabular}{|c|c|}
\hline $\mathrm{ACV}$ & $\delta$-(L- $\alpha$-Aminoadipyl)-L-cysteinyl-D-valine \\
\hline 6-APA & 6-Aminopenicillanic acid \\
\hline$c_{\text {total,cyt }}$ & Total intracellular concentration of POA [mM] \\
\hline $\begin{array}{l}c_{\text {undiss,cyt }} \\
\text { 8-HPA }\end{array}$ & $\begin{array}{l}\text { Intracellular concentration of undissociated POA }[\mu \mathrm{M}] \\
8 \text {-Hydroxypenillic acid }\end{array}$ \\
\hline IPN & Isopenicillin $\mathrm{N}$ \\
\hline$K_{\mathrm{m}}$ & Michaelis-Menten constant $[\mu \mathrm{M}$ or $\mathrm{mM}]$ \\
\hline$K_{\mathrm{m}, \text { total }}$ & $\begin{array}{l}\text { Overall apparent Michaelis-Menten constant for the sequence of reactions leading to } \\
\text { the incorporation of cytoplasmic POA into penicillin } \mathrm{V}[\mathrm{mM}]\end{array}$ \\
\hline$K_{\mathrm{m}, \text { undiss }}$ & $\begin{array}{l}\text { Overall apparent Michaelis-Menten constant for the sequence of reactions leading to } \\
\text { the incorporation of cytoplasmic POA into penicillin V when assuming undissociated } \\
\text { POA as being the only substrate }[\mu \mathrm{M}]\end{array}$ \\
\hline $\mathrm{OPC}$ & 6-Oxopiperidine-2-carboxylic acid \\
\hline POA & Phenoxyacetic acid \\
\hline$r_{\mathrm{ACV}}$ & Specific net formation rate of ACV [nmol (g dry wt $\left.)^{-1} \mathrm{~h}^{-1}\right]$ \\
\hline$r_{6-\mathrm{APA}}$ & Specific net formation rate of 6-APA $\left[\mu \mathrm{mol}(\mathrm{g} \text { dry } w \mathrm{t})^{-1} \mathrm{~h}^{-1}\right]$ \\
\hline$r_{8-\mathrm{HPA}}$ & Specific net formation rate of 8 -HPA $\left[\mu \mathrm{mol}(\mathrm{g} \text { dry } w t)^{-1} \mathrm{~h}^{-1}\right]$ \\
\hline$r_{\text {IPN }}$ & Specific formation rate of IPN $\left[\mu \mathrm{mol}(\mathrm{g} \text { dry } w t)^{-1} \mathrm{~h}^{-1}\right]$ \\
\hline$r_{\text {OPC }}$ & Specific formation rate of OPC $\left[\mu \mathrm{mol}(\mathrm{g} \text { dry } w t)^{-1} \mathrm{~h}^{-1}\right]$ \\
\hline$r_{\mathrm{p}}$ & Specific production rate of penicillin $V\left[\mu \mathrm{mol}(\mathrm{g} \text { dry } w \mathrm{t})^{-1} \mathrm{~h}^{-1}\right]$ \\
\hline$r_{\mathrm{p}, \max }$ & Maximum specific production rate of penicillin $V\left[\mu \mathrm{mol}(\mathrm{g} \text { dry } w t)^{-1} \mathrm{~h}^{-1}\right]$ \\
\hline
\end{tabular}

dissolved in $1 \mathrm{M} \mathrm{NaOH}$ followed by incubation for $5 \mathrm{~min}$ at $25^{\circ} \mathrm{C}$. Standards and samples were subsequently diluted in $50 \mathrm{mM}$ phosphate buffer, $\mathrm{pH} 2 \cdot 5$, to a maximum concentration of $250 \mu \mathrm{M}$. Volumes of $20 \mu \mathrm{l}$ were derivatized with monobromobimane by adding $60 \mu \mathrm{l}$ freshly prepared derivatization reagent containing $18 \mu \mathrm{l} 0.1 \mathrm{M}$ monobromobimane (Thiolyte reagent; Calbiochem-Novabiochem) in acetonitrile (Merck) (this preparation can be stored for $14 \mathrm{~d}$ at $4^{\circ} \mathrm{C}$ if kept dark, $12 \mu \mathrm{l} 0.25 \mathrm{M}$ diethylenetriaminepentaacetic acid (Sigma) in $1 \mathrm{M} \mathrm{NaOH}$ (stored at $4^{\circ} \mathrm{C}$ ) and $570 \mu \mathrm{l} 0.4 \mathrm{M}$ HEPPS buffer (Sigma), pH 8.0 (stored at $4^{\circ} \mathrm{C}$ ) and incubated in the dark for $15 \mathrm{~min}$ at $25^{\circ} \mathrm{C}$. Derivatization was stopped by adding $20 \mu \mathrm{l} 1 \mathrm{M}$ methanesulfonic acid (Sigma).

Symbols and abbreviations. The symbols and abbreviations used in this paper are shown in Table 1.

\section{RESULTS AND DISCUSSION}

\section{Production of penicillin $\mathrm{V}$}

A series of continuous cultivations with a highpenicillin-yielding strain of $P$. chrysogenum was conducted on a chemically defined medium with glucose as the growth-limiting component at a fixed dilution rate of $0.05 \mathrm{~h}^{-1}$. The penicillin $\mathrm{V}$ sidechain precursor POA was added to the feed in various concentrations between 0 and $6.5 \mathrm{~g} \mathrm{l}^{-1}$ and as soon as the feeding was initiated biosynthesis of penicillin $\mathrm{V}$ started. The strain used is known for its capability to oxidize POA into $p$-hydroxyPOA to some extent during fed-batch cultivations on a complex medium, and due to the rather broad substrate specificity of the acyltransferase, incorporation of $p$-hydroxyPOA into $p$-hydroxypenicillin $V$ is observed (Jørgensen et al., 1995). During continuous cultivation on the chemically defined medium, oxidation of POA was measured as well, but at a very low level:

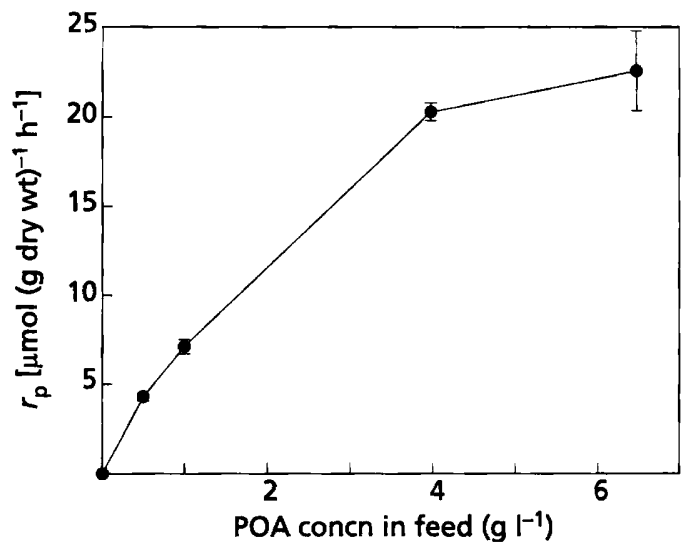

Fig. 1. Specific production rate of penicillin $V\left(r_{p}\right)$ as a function of the POA concentration in the feed at steady state in glucoselimited continuous cultivations operated at a dilution rate of $0.05 \mathrm{~h}^{-1}($ mean \pm SD; $n=10)$.

$p$-hydroxyPOA accounted for less than $0.5 \%$ of the residual POA concentration. Formation of $p$-hydroxypenicillin $\mathrm{V}$ was therefore also insignificant. Likewise, the level of penicilloic acid $\mathrm{V}$ formed by hydrolysis of penicillin $\mathrm{V}$ was very low. The difference between the POA concentration in the feed and the residual POA concentration in the bioreactor matched the amount of POA incorporated into penicillin $\mathrm{V}$, which implies that POA is not metabolized by the applied strain of $P$. chrysogenum.

Fig. 1 shows the influence of the POA concentration in the feed on the steady-state specific production rate of penicillin $\mathrm{V}\left(r_{\mathrm{p}}\right)$. At a POA concentration of $6.5 \mathrm{~g} \mathrm{l}^{-1} r_{\mathrm{p}}$ 


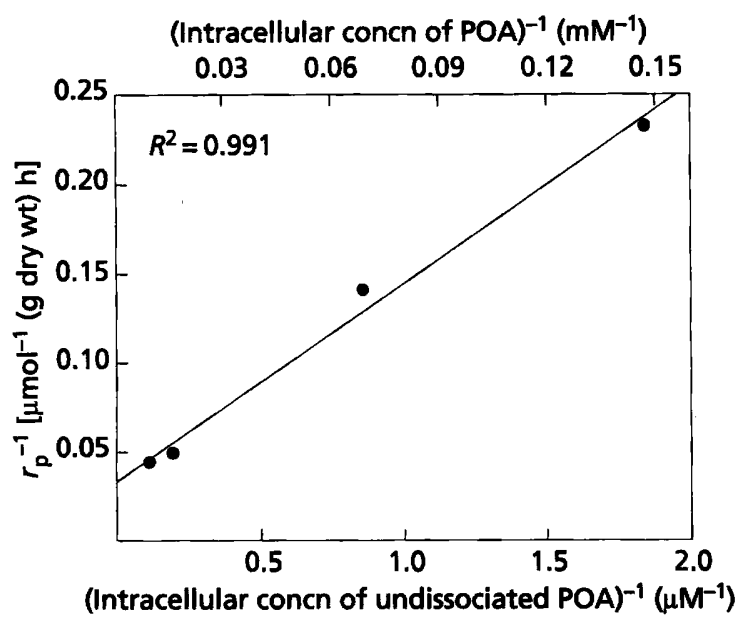

Fig. 2. Lineweaver-Burk plot of the specific production rate of penicillin $V\left(r_{p}\right)$ as a function of the intracellular concentrations of POA and undissociated POA. The intracellular concentrations were calculated as described by Henriksen et al. (1998) from the experimental data on the specific growth rate and $r_{p}$.

is $22 \cdot 4 \pm 2 \cdot 2 \mu \mathrm{mol}$ (g dry $w t^{-1} \mathrm{~h}^{-1}$ and the yield coefficient on glucose $\left(Y_{\text {sp }}\right)$ is $0.098 \pm 0.008 \mathrm{C}$-mol C$\mathrm{mol}^{-1}$. Under these conditions only $7 \%$ of the POA is incorporated into penicillin $\mathrm{V}$ and the residual POA concentration is as high as $6.0 \mathrm{~g} \mathrm{l}^{-1}$. When the POA concentration is lowered, $r_{p}$ drops dramatically, to a value of $4.3 \pm 0.2 \mu \mathrm{mol}(\mathrm{g} \text { dry wt })^{-1} \mathrm{~h}^{-1}$ at a POA concentration of $0.5 \mathrm{gl}^{-1}$, corresponding to a $Y_{\mathrm{sp}}$ of only $0.0197 \pm 0.0008 \mathrm{C}-\mathrm{mol} \mathrm{C}^{-\mathrm{mol}^{-1}}$. A POA concentration of $0.5 \mathrm{~g} \mathrm{l}^{-1}$ should, however, theoretically be sufficient to obtain the same $r_{\mathrm{p}}$ as observed for a POA concentration of $6.5 \mathrm{~g} \mathrm{l}^{-1}$. Still, only $19 \%$ of the POA is utilized for penicillin $\mathrm{V}$ production, leading to a residual POA concentration of $0.4 \mathrm{~g} \mathrm{l}^{-1}$. These findings indicate the presence of a step with very low affinity towards POA in the sequence of transport and reactions leading to the incorporation of exogenous POA into penicillin V. Furthermore, they demonstrate that a high POA concentration is crucial for obtaining a high productivity of penicillin V. Results from the penicillin strain improvement programme of Panlabs (Lein, 1986) indicate that high POA concentrations are a requirement for obtaining high penicillin $\mathrm{V}$ titres, though some of the earlier strains in the programme were less tolerant towards POA and showed a decrease in titre above $0.9 \%$ potassium-POA $\left(\sim 7.2 \mathrm{~g} \mathrm{POA} \mathrm{l}^{-1}\right)$.

Mathematical expressions for calculating the theoretical intracellular concentrations of undissociated and dissociated POA have previously been derived (Henriksen et al., 1998). By applying these expressions to the experimentally obtained data, $r_{p}$ can be expressed as a function of both intracellular forms of POA, as depicted in the Lineweaver-Burk double reciprocal plot shown in Fig. 2. At a typical intracellular $\mathrm{pH}$ of $\mathbf{7 \cdot 2}$, intracellular POA will almost exclusively be present as the dissociated form and only $0.008 \%$ will be undissociated. The overall incorporation rate of exogenous POA into penicillin $\mathrm{V}$ is seen to obey Michaelis-Menten type saturation kinetics. Thus, $r_{p}$ can be expressed as equation (1), with, respectively, $r_{\mathrm{p}, \max }, c_{\mathrm{total}, \mathrm{cyt}}$ and $c_{\text {undiss, cyt }}$ as the maximum specific production rate of penicillin $V$, the total intracellular POA concentration and the intracellular concentration of undissociated POA. $K_{\mathrm{m} \text {,total }}$ and $K_{\mathrm{m} \text {,undiss }}$ are the two Michaelis-Menten saturation constants.

$$
\begin{aligned}
r_{\mathrm{p}} & =r_{\mathrm{p}, \max } \frac{c_{\mathrm{total}, \mathrm{cyt}}}{c_{\text {total,cyt }}+K_{\mathrm{m}, \text { total }}} \\
& =r_{\mathrm{p}, \max } \frac{c_{\text {undiss,cyt }}}{c_{\text {undiss, cyt }}+K_{\mathrm{m}, \text { undiss }}}
\end{aligned}
$$

When the experimental data are fitted to equation (1), values of $42 \mathrm{mM}$ and $3.3 \mu \mathrm{M}$ are obtained for $K_{\mathrm{m} \text {,total }}$ and $K_{\mathrm{m} \text {,undiss, }}$, respectively. The high value for $K_{\mathrm{m} \text {,total }}$ confirms the low affinity towards POA as sidechain precursor for penicillin synthesis. If the enzyme responsible for the CoA-ester activation of POA exclusively activated the undissociated form of POA, as discussed by Henriksen et al. (1998) as an explanation for the sidechain precursor preference observed in $P$. chrysogenum, this enzyme possesses a very high affinity towards undissociated POA, as reflected by the low $K_{\mathrm{m}, \text { undiss }}$

\section{Formation of by-products related to the penicillin biosynthetic pathway}

The production of penicillin is known to be accompanied by the formation of a series of different byproducts related to the penicillin biosynthetic pathway (Jørgensen et al., 1995). Some of the by-products are simply intermediates from the pathway, i.e. ACV, IPN and 6-APA, or derived from these, for example 8-HPA, which is formed by carboxylation of 6-APA. Others are degradation products of penicillin, for example penicilloic acid. Finally, by-products such as OPC, the $\delta$ lactam form of $\alpha$-aminoadipic acid, are formed without a clear linkage to penicillin biosynthesis. The specific formation rates of ACV, IPN, 6-APA, 8-HPA and OPC $\left(r_{\mathrm{ACV}}, r_{\mathrm{IPN}}, r_{6-\mathrm{APA}}, r_{8-\mathrm{HPA}}\right.$ and $r_{\mathrm{OPC}}$, respectively) are depicted in Fig. 3. Since the carboxylation of 6-APA into 8-HPA is a rapid, non-enzymic reaction (Henriksen et al., 1997), the formation of 6-APA and 8-HPA has been treated as a single reaction. The specific formation rates of 6-APA and 8-HPA drop dramatically as soon as POA appears in the extracellular medium and they decrease with increasing POA concentration until at a POA concentration in excess of $4 \mathrm{~g} \mathrm{l}^{-1}$ they become constant. This coincides with the levelling off of the specific production rate of penicillin V, as seen in Fig. 1. These observations clearly indicate that the supply of activated sidechain precursor at this point is no longer ratecontrolling for penicillin biosynthesis. Likewise, $r_{\text {IPN }}$ decreases with increasing POA concentration, whereas the secretion of intracellular ACV increases at high POA concentrations though at a level significantly lower than observed for any of the other by-products. Finally, 

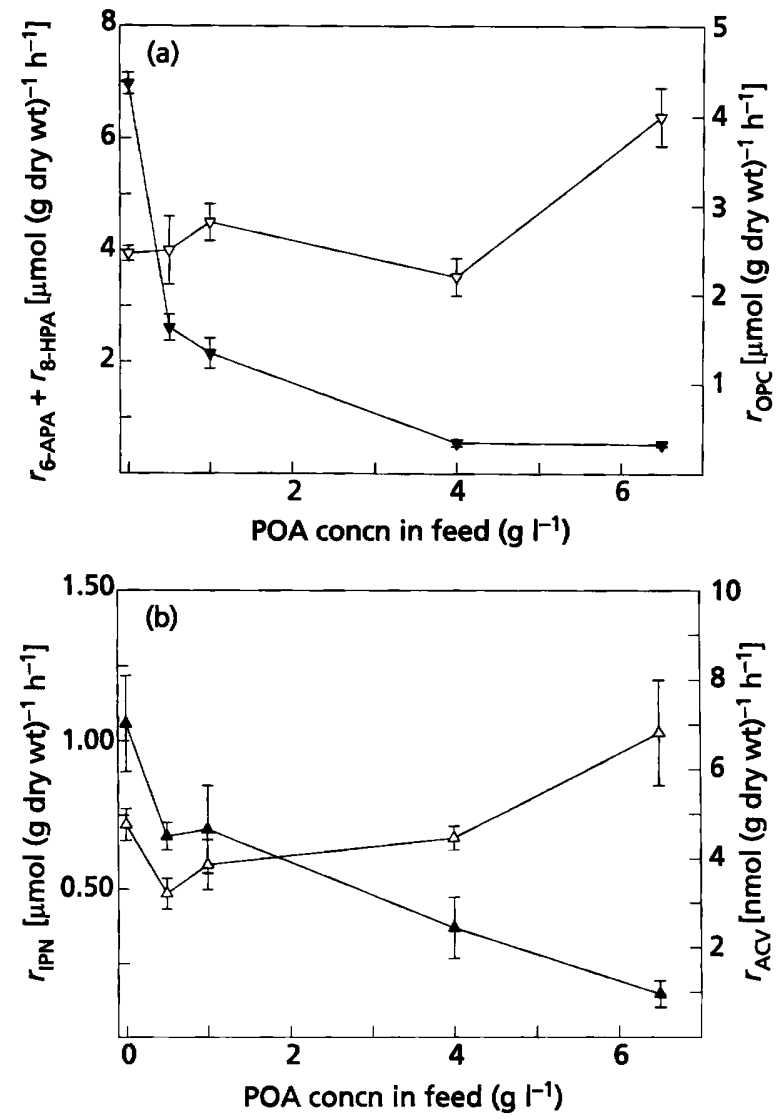

Fig. 3. Influence of the POA concentration on the specific formation rate of by-products and intermediates related to the penicillin biosynthetic pathway (mean $\pm S D, n=5$ ). (a) Specific formation rates of the by-products 6-APA $\left(r_{6-A P A}\right)$ and 8-HPA $\left(r_{8-H P A}\right)(\nabla)$ and OPC $\left(r_{\text {OPC }}\right)(\nabla)$. (b) Specific formation rates of the pathway intermediates IPN $\left(r_{\text {IPN }}\right)(\Delta)$ and ACV $\left(r_{\mathrm{ACV}}\right)(\triangle)$. Note that $r_{A C}$ is expressed in $\mathrm{nmol}(\mathrm{g} \text { dry } w t)^{-1} \mathrm{~h}^{-A C V}$ and all other rates in $\mu \mathrm{mol}(\mathrm{g} \text { dry } \mathrm{wt})^{-1} \mathrm{~h}^{-1}$.

formation of OPC is constant at low POA concentrations but increases at high concentrations of POA. It is worth noting that OPC is the dominant by-product in cultivations with POA.

Fig. 4 shows the normalized steady-state distribution of net fluxes in the penicillin biosynthetic pathway at a POA concentration of $6.5 \mathrm{~g} \mathrm{l}^{-1}$ in the feed. From $100 \mathrm{~mol}$ ACV formed in the initial biosynthetic step in the pathway, as much as $97.1 \mathrm{~mol}$ ends up in penicillin $\mathrm{V}$, of which $2.0 \mathrm{~mol}$ is lost as penicilloic acid $\mathrm{V}$ by hydrolysis. The level of by-product formation is significantly lower than observed by Jørgensen et al. (1995) during a fedbatch cultivation with the same strain but on a complex medium.

\section{Concluding remarks}

According to Henriksen et al. (1998), concentrations of POA up to $6.5 \mathrm{~g} \mathrm{l}^{-1}$ at $\mathrm{pH} 6.50$ do not cause any negative physiological effects, such as uncoupling of the plasma membrane potential upon uptake from the extracellular medium, on a high-penicillin-yielding strain of $P$.

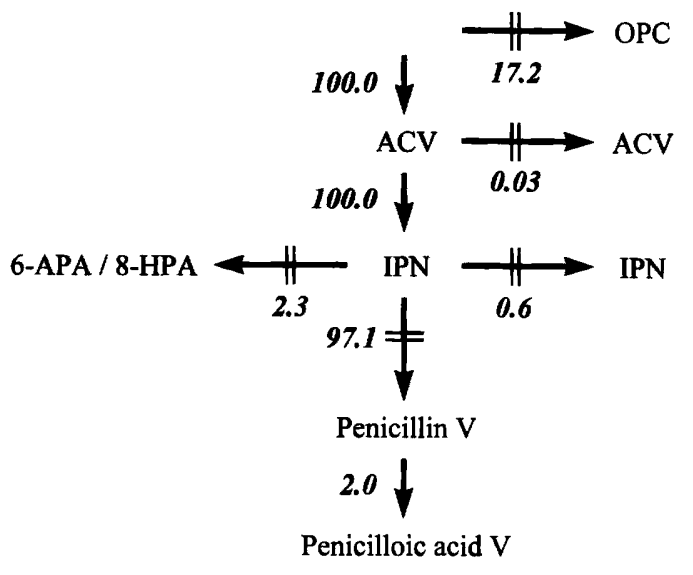

Fig. 4. Steady-state distribution of net fluxes in the penicillin biosynthetic pathway at a POA concentration of $6.5 \mathrm{~g} \mathrm{I}^{-1}$ in the feed. All fluxes have been normalized with respect to the rate of ACV formation in the initial enzymic step [23.3 $\mu \mathrm{mol}$ ( $g$ dry $w()^{-1} h^{-1}$. Bars indicate fluxes across the plasma membrane.

chrysogenum. In the present study it was established that high concentrations of POA are necessary for obtaining high productivities of penicillin $\mathrm{V}$, since the reactions that form the sequence responsible for incorporation of the sidechains into the different penicillins have an overall low affinity towards POA. Furthermore, high POA concentrations tend to decrease the overall rate of formation of by-products related to the penicillin biosynthetic pathway. It is, however, questionable whether concentrations of POA significantly higher than $6.5 \mathrm{~g} \mathrm{l}^{-1}$ are economically feasible in industrial fed-batch penicillin cultivations, unless the excess POA concentration is consumed at the end of the cultivation.

\section{REFERENCES}

Alvarez, E., Meesschaert, B., Montenegro, E., Gutiérrez, S., Dlez, B., Barredo, J. L. \& Martin, J. F. (1993). The isopenicillin-N acyltransferase of Penicillium chrysogenum has isopenicillin-N amidohydrolase, 6-aminopenicillanic acid acyltransferase and penicillin amidase activities, all of which are encoded by the single penDE gene. Eur J Biochem 215, 323-332.

Christensen, L. H., Nielsen, J. \& Villadsen, J. (1991). Delay and dispersion in an in-situ membrane probe for bioreactors. Chem Eng Sci 46, 3304-3307.

Christensen, L. H., Mandrup, G., Nielsen, J. \& Villadsen, J. (1994). A rubost LC method for measurement of medium components during penicillin fermentations. Anal Chim Acta 296, 51-62.

Christensen, L. H., Henriksen, C. M., Nielsen, J., Villadsen, J. \& Egel-Mitani, M. (1995). Continuous cultivation of Penicillium chrysogenum. Growth on glucose and penicillin production. $J$ Biotechnol 42, 95-107.

Henriksen, C. M., Holm, S. S., Schipper, D., Jørgensen, H. S., Nielsen, J. \& Villadsen, J. (1997). Kinetic studies on the carboxylation of 6-amino-penicillanic acid to 8-hydroxy-penillic acid. Proc Biochem 32, 85-91.

Henriksen, C. M., Nielsen, J. \& Villadsen, J. (1998). Modelling of the protonophoric uncoupling by phenoxyacetic acid of the 
plasma membrane potential of Penicillium chrysogenum. Biotechnol Bioeng (in press).

Jørgensen, H. S., Nielsen, J., Villadsen, J. \& Møllgaard, H. (1995). Analysis of the penicillin $\mathrm{V}$ biosynthesis during fed-batch cultivations with a high yielding strain of Penicillium chrysogenum. Appl Microbiol Biotechnol 43, 123-130.

Lein, J. (1986). The Panlabs penicillin strain improvement program. In Overproduction of Microbial Metabolites, pp.
105-139. Edited by Z. Vanek \& Z. Hostálek. Boston, MA: Butterworths.

Nielsen, J. \& Villadsen, J. (1993). Bioreactors: description and modelling. In Biotechnology, 2nd edn, vol. 3, pp. 77-104. Edited by G. Stephanopoulos. Weinheim: VCH.

Received 28 January 1998; accepted 9 March 1998. 